\title{
The virulence of the entomopathogenic fungi on the predatory species, Cryptolaemus montrouzieri Mulsant (Coleoptera: Coccinellidae) under laboratory conditions
}

\author{
Ghada S. Mohamed
}

\begin{abstract}
The objective of this study was to assess the survivorship and fecundity of the newly emerged females of the predatory species, Cryptolaemus montrouzieri Mulsant (Coleoptera: Coccinellidae), exposed to $L_{50}$ of the entomopathogenic fungi (EPF); Beauveria bassiana and Metarhizium anisopliae under laboratory status. The virulence of the EPF was evaluated, using the dipping implementation technique. $L C_{50}$ values were determined based on the concentration-response analysis. The $L C_{50}$ value for the predator's females was $3 \times 10^{9}$ and $6 \times 10^{8}$ conidia/ml for B. bassiana and M. anisopliae, respectively. Life table and population parameters were the models to estimate survivorship of each stage of $C$. montrouzieri. Results demonstrated that the highest mortality rates $20.35,27.40$, and $29.45 \%$ occurred during the larval stage, whereas the total mortality rates attained $28.57,38.61$, and $44.66 \%$ for the control, B. bassiana, and M. anisopliae, respectively. For fecundity, the final proliferation average $\left(R_{0}\right)$ of the population was 338.82, 155.99, and 115.55; mean generation time (T) was 43.76, 60.95, and 76.78; natural increase $\left(r_{m}\right)$ was $0.13,0.08$, and 0.06 ; the steady rate of increase $(\lambda)$ was $1.14,1.08$, and 1.06; and the required time to double the population $\left(D_{T}\right)$ was $5.33,8.66$, and 11.55 days for the control, B. bassiana, and M. anisopliae, respectively.
\end{abstract}

Keywords: Entomopathogenic fungi, Beauveria bassiana, Metarhizium anisopliae, Cryptolaemus montrouzieri, Life table, Effect

\section{Background}

The coccinellid beetles occupied a major economic significance in agro-ecosystem, where they can be powerfully utilized in the biological control of numerous detrimental insects. The ladybird, Cryptolaemus montrouzieri Mulsant (Coleoptera: Coccinellidae), is an active natural enemy of mealybugs that acting as a significant predator inside the IPM of mealybug pests in diverse cultivations. This beetle has been noted to prey on about 21 mealybug species (Jiang et al., 2009) and exceedingly to be applied as a biotic control factor in regions, where mealybugs such as Planococcus citri (Risso), Maconellicoccus hirsutus Green,

Correspondence: d.ghada1@yahoo.com

Plant Protection Department, Faculty of Agriculture, South Valley University, Qena, Egypt
Phenacoccus solenopsis Tinsley, and Ferrisia virgata outbreaks be found (Kaur and Virk, 2012).

Utilizing the entomopathogenic fungi (EPF), Beauveria bassiana, Metarhizium anisopliae, and Verticillium lecanii as biopesticides have been greatly applied for pest control (Faria and Wraight, 2007).

One of the substantial facts that should be taken into account in the utilization of EPF as biological control agents is their harmony with other biological control factors. In spite of some EPF are renowned, particularly some of those relate to Deuteromycotina, they have a rather vast range of hosts from numerous insect orders and natural enemies (Inglis et al., 2001). Integration between EPF and predators is needed to increase the role of bioagents and decrease the hazards to the environment.

\section{Springer Open}

(c) The Author(s). 2019 Open Access This article is distributed under the terms of the Creative Commons Attribution 4.0 International License (http://creativecommons.org/licenses/by/4.0/), which permits unrestricted use, distribution, and reproduction in any medium, provided you give appropriate credit to the original author(s) and the source, provide a link to the Creative Commons license, and indicate if changes were made. 
B. bassiana and $M$. anisopliae give rise into white and green muscardine disease in the enormous extent of insects and are presently utilized inside the greenhouse and orchard crops for the management of agricultural arthropod pests involving whiteflies, aphids, thrips, psyllids, mealybugs, and weevils (Thungrabeab et al., 2006). In the status of EPF, the fatal and sub-fatal influences of the pathogen on useful insects (predators and parasitoids) considering fertility, lifespan period, and survivorship are in need to be estimated. Life table investigations supply a potent method for amount estimation of naturalistic enemies to elaborate characterization agespecified mortality of individuals in inhabitants (Luck et al., 1988). When knowledge about the quality of insect fertility and mortality that occur at any age is obtainable, the influence of the naturalistic enemy is skillfully obvious on the one hand with its impact on measuring the pest population development rate (van Driesche and Bellows, 1996).

There is extremely slight information on the appropriate employment of B. bassiana and M. anisopliae on $C$. montrouzieri for integrated pest management of Planococcus ficus (Signoret) according to utilizing the life table technique.

Therefore, the target of this investigation is to estimate the impact of B. bassiana and M. anisopliae on C. montrouzieri via investigating the predator's biological parameters.

\section{Materials and methods}

\section{Culture of prey and predator}

The vine mealybug, Planococcus ficus (Signoret), was reared on pumpkins to gain a colony for the duration of work as the method described by Pang and Gordon (1986). Pumpkins were washed by water to remove dust and dried with tissues. The ovisacs, crawlers, and adults of the vine mealybug gained from infested grapevine plants at Qena Governorate, Egypt, and were transmitted onto the pumpkins. Infested pumpkins were preserved in a cylindrical plastic crate $(30 \mathrm{~cm}$ diameter). They were maintained at a relative humidity of $45 \pm 5 \%$, a temperature of $25 \pm 1{ }^{\circ} \mathrm{C}$, and a $16: 8$ day time, darkness period. Subsequently, the numbers of vine mealybugs had an excess on pumpkins then adequate C. montrou$z i e r i$ adults were released on the vine mealybugs. Adults and eggs of the predator that were utilized for the trials were acquired after completing one generation of rearing.

\section{Applied fungi}

Two species of the EPF, B. bassiana and M. anisopliae, were obtained from Assiut University Mycological Center (AUMC), Egypt. The two fungal species were preserved in a refrigerator pending utilizing them for conidiospores output.

\section{Conidiospore production}

The fungi $B$. bassiana and $M$. anisopliae were grown on a medium of Potato Dextrose Agar (PDA) which poured into Petri plates. A hemocytometer was applied to calculate the concentration of conidia in the stock suspension. After that, dilution was carried out to obtain the required concentrations of the conidia (Nazir et al., 2007).

\section{Bioassay}

Three concentrations of conidial suspension $\left(5 \times 10^{7}, 5\right.$ $\times 10^{8}$, and $5 \times 10^{9}$ conidia $/ \mathrm{ml}$ ) from B. bassiana and $M$. anisopliae were prepared. All bioassay trials were executed in the laboratory at $25 \pm 1{ }^{\circ} \mathrm{C}$. Ten new emerged females of $C$. montrouzieri were handled by immersing them for $5 \mathrm{~s}$ in the conidial suspension in $50 \mathrm{ml}$ conical flasks. After immersing inside the suspension, the insect predators were maintained by the vine mealybug into a Petri dish $(9 \times 1.5 \mathrm{~cm})$. Thereafter, they were preserved for 7 days at $25^{\circ} \mathrm{C}$ and $80-90 \%$ RH. A treatment with sterile distilled water $+0.05 \%$ Triton X-100 without fungal conidia was utilized as a control. Four duplicates for each treatment, containing 10 insects, were used. Lifeless insects were numbered next 1, 3, 5, and 7 days. Results were analyzed by probit analysis employing SPSS computer program to estimate $\mathrm{LC}_{50}$ values.

\section{Effect of $\mathrm{LC}_{50}$ concentration on life table parameters of the treated unmated females of $C$. montrouzieri}

Twenty-five recent female predators staying lively after $72 \mathrm{~h}$ from treating with the $\mathrm{LC}_{50}$ concentration of the fungi were applied for this experiment. Every single female was displayed on an untherapy male from the supplies settlement, singularly. The lifeless males were substituted with life males. In the whole testing, the diverse phases of the vine mealybug and $P$. ficus were extended like a nutrition exporter. The death rate and oviposition were registered every day till the demise of the final female in treatments and controls together. Life and fecundity tables were applied to estimate the influence of the $\mathrm{LC}_{50}$ concentrations of the fungi on preovipositional, ovipositional, and post-ovipositional periods and daily fecundity and longevity of $C$. montrouzieri. Life and fecundity tables were the subsequent accomplishment of Southwood (1978). Life table coefficients were calculated as follows:

$x$ : Age cohort in factors of time (days)/growing stage

$l_{x}$ : Number of staying vivid individuals at the beginning of age category $(x)$

$L_{x}$ : Number of individuals alive between age and the age period that followed 
$d_{x}$ : Number of death through age period $x$

100qx: Percent ostensible of the death-rate, 100qx $=$

$\left(d_{x} / l_{x}\right) 100$

$S_{x}$ : Survival stage rate within the stage

$T_{x}$ : The overall figure of age $x$ units after the age $x$

ex: Life anticipated for individuals of age $x, e_{x}=T_{x} / l_{x}$

Age-specific fertility table was constructed with the following columns:

$X$ : Actual female age (time from eggs).

$m_{x}$ : age-specific fecundity, the number of living females born per female in each age period

$R_{o}$ : The final propagation rates, $R_{o}=\Sigma l_{x} m_{x}$

$T$ : Average generation period, $T=\ln R_{o} / r_{m}$

$D_{T}$ : Twice the amount of time, the number of days required by a population to double, $D_{T}=\ln 2 / r_{m}$

$r_{m}$ : The instinctive ability for the augmentation, $r=\ln$ $R_{o} / T$

$\lambda$ : The limited average of augmentation, $\lambda=e^{r}$

\section{Results and discussion}

Dose-response bioassay

Results of the pathogenicity test showed that the treatments with the two entomopathogenic fungi reduced the number of predator females C. montrouzieri. The $\mathrm{LC}_{50}$ values and the slope of are shown in (Table 1).

The lowest $\mathrm{LC}_{50}$ value $\left(6 \times 10^{8}\right.$ conidia/ml $)$ was recorded for M. anisopliae treatment. As stated about the $\mathrm{LC}_{50}$ values, $M$. anisopliae isolate possessed a great influence against the predator females, followed by $B$. bassiana. Ibrahim et al. (2011) reported that different isolates of $M$. anisopliae were generally virulent to $C$. montrouzieri predator. No death was recorded in the control. All concentrations that were used from the previous fungi had a potential effect on the female of $\mathrm{C}$. montrouzieri. The mortality rate of the female depended on the species of fungi used and also on the dose concentration. The mortality rate at the end of the experiment, resulting from various concentrations of the EPF, is illustrated in (Fig. 1). The accumulative mortality of $\mathrm{C}$. montrouzieri females displayed on isolates of the fungi extended from 25 and $52 \%$ to 32.5 and $65 \%$ for B. bassiana and M. anisopliae, respectively.

The study outcome is similar to the results of Thungrabeab and Tongma (2007) who found that M. anisopliae was more effective than $B$. bassiana against Coccinella

Table $1 \mathrm{LC}_{50}$ values of entomopathogenic fungi on the female of Cryptolaemus montrouzieri

\begin{tabular}{|c|c|c|c|c|}
\hline \multirow[t]{2}{*}{ Fungal isolates } & \multirow{2}{*}{$\begin{array}{l}\mathrm{LC}_{50} \\
\text { conidia/ } \\
\mathrm{ml}\end{array}$} & \multicolumn{2}{|c|}{ Confidence limits } & \multirow{2}{*}{$\begin{array}{l}\text { Slope } \pm \\
\text { S.E }\end{array}$} \\
\hline & & Lower & Upper & \\
\hline Beauveria bassiana & $3 \times 10^{9}$ & $7 \times 10^{8}$ & $2 \times 10^{12}$ & $0.37 \pm 0.15$ \\
\hline Metarhizium anisopliae & $6 \times 10^{8}$ & $1 \times 10^{8}$ & $3 \times 10^{9}$ & $0.41 \pm 0.15$ \\
\hline
\end{tabular}

septempunctata L. Also, Trizelia et al. (2017) noticed that up to $(67.50 \%)$ mortality rate of different larval instars of the predator, Menochilus sexmaculatus Fabricius occurred by various strains of $M$. anisopliae. Similarly, Er et al. (2008) reported that $M$. anisopliae caused (47.61\%) mortality rate to C. septempunctata adults.

A toxin known as destruxin, which is produced by $M$. anisopliae and B. bassiana through the infection was believed to be the reason of $C$. montrouzieri death. Destruction affected target cell organelles (mitochondria, endoplasmic reticulum, and nuclear membrane) and caused cells paralysis. It also affected the mesenteron, malphigian tubes, and tissue larval hemocyte disfunction (Tanada and Kaya, 1993).

There is a close relationship between the conidiospores concentrations of B. bassiana and $M$. anisopliae and the proportion of the noticed mortality. The minimum fungal concentration $\left(5 \times 10^{7}\right.$ conidia/ml $)$ caused less death percentages (25 and 32.5\%) for C. montrouzieri females.

Consequently, the weak potency of fungi could be due to the faint conidial concentrations, which the maximum concentration was $5 \times 10^{9}$ conidia/ml of the two tested fungi that brought out high mortality percentages of 52 and $65 \%$, respectively. Scorsetti et al. (2012) compared the ability of $B$. bassiana and these concentrations on Eriopis connexa (Germar) predator of aphids (Hemiptera: Aphididae) and stated that all E. connexa stages utilized were sensitive to $B$. bassiana. Thungrabeab and Tongma (2007) found relationships between the virulence of B. bassiana and M. anisopliae and their concentrations on non-target insects.

Effect of $\mathrm{LC}_{50}$ concentration values of $B$. bassiana and $M$. anisopliae on biological parameters and reproductive performance of the treated unmated females of $C$. montrouzieri

\section{Age-specific survival life table}

The percentage of mortality in egg stage registered (12.64, 15.05 , and $6.98 \%$ ) on emerged female individuals after treatment with $\mathrm{LC}_{50}$ concentration of EPF than in the control, respectively, due to the effect of EPF on physiological causes leading to infertility as well as their effect on genetic factors. In line with obtained outcomes, Nalepa and Weir (2007) explained that the percentage of mortality during the egg phase was 14.66 and $11.53 \%$, when evaluating the effect of EPF, $M$. anisopliae and Hesperomyces virescens on the life table of the coccinellid, Harmonia axyridis.

The highest rates of mortality found in young larval instar and then began to decline gradually in the elderly instars (Tables 2, 3, and 4). The highest mortality rate was registered in the 1st instar larvae (10.10, 9.71, and 


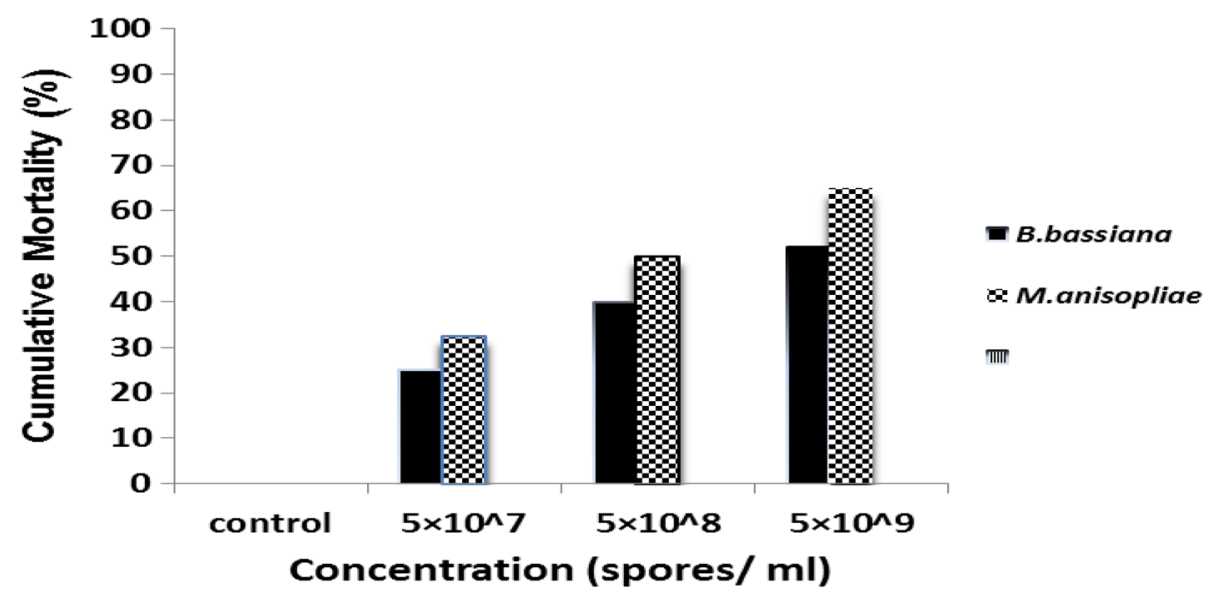

Fig. 1 Accumulative mortality (\%) of Cryptolaemus montrouzieri adult

6.35), followed by 2nd instar larvae (8.84, 8.25, and $5.71)$, 3rd instar larvae $(6.63,2.91$, and 3.49), and 4th instar larvae $(6.25,2.43$, and 2.86$)$ for female individuals, which remained alive $72 \mathrm{~h}$ after exposure to $\mathrm{LC}_{50}$ concentration of B. bassiana and M. anisopliae than in the control, respectively.

The larval stage registered the highest mortality rate due to the length of the larval life compared to the rest of the other stages. The mortality percentage of the larval stage registered $(27.40,29.45$, and $20.35 \%)$ after treatment with $B$. bassiana and $M$. anisopliae than in the control, respectively.

The response of the first instar larvae to the effect of different fungus species was due to the heterogeneity of the cuticle layer at these instars. In contrast, the weak effect of different types of fungi on the adult stage of this insect may be due to the sclerotization and tanning of the cuticle layer that impeded the penetration of fungal hyphae. Thungrabeab and Tongma (2007) also suggested that the cuticle of $C$. septempunctata had the biggest influence on the penetration of B. bassiana and $M$. anisopliae.

Table 2 Life table of Cryptolaemus montrouzieri females treated with $\mathrm{LC}_{50}$ concentration of Beauveria bassiana

\begin{tabular}{llllllll}
\hline$x$ & $I_{x}$ & $L_{x}$ & $d_{x}$ & $100_{\mathrm{qx}}$ & $S_{x}$ & $T_{x}$ & $e_{x}$ \\
\hline Eggs & 277 & 242.5 & 35 & 12.64 & 87.36 & 1043.5 & 3.77 \\
1st instar & 208 & 194.5 & 21 & 10.1 & 89.9 & 801 & 3.85 \\
2nd instar & 181 & 173.5 & 16 & 8.84 & 91.16 & 606.5 & 3.35 \\
3rd instar & 166 & 155 & 11 & 6.63 & 93.37 & 433 & 2.61 \\
4th instar & 144 & 131 & 9 & 6.25 & 93.75 & 278 & 1.93 \\
$\quad$ Pupae & 118 & 103 & 15 & 12.71 & 87.29 & 147 & 1.25 \\
Adult & 88 & 33 & & & & & \\
\hline
\end{tabular}

Overall, data in Tables 2, 3, and 4 presented the total mortality rate of C. montrouzieri (38.61, 44.66, and $28.57 \%$ ), when it is exposed to B. bassiana, $M$. anisopliae, and the control, respectively. The investigation moved in the identical line of Trizelia et al. (2017) who realized that the total percentage of the mortality of Menochilus sexmaculatus Fabricius ranged from 27.50 to $67.50 \%$ after treatment with Metarhizium spp. isolates.

\section{Age-specific fecundity table}

Age-specific survivorship $\left(l_{x}\right)$ and fertility $\left(m_{x}\right)$ of $C$. montrouzieri on resulted females remained alive after $72 \mathrm{~h}$ after exposing to $\mathrm{LC}_{50}$ concentration of $B$. bassiana and $M$. anisopliae and in the control are shown in Fig. 2.

The initial female emerged on the days 46,54 , and 33 and the precocious egg deposition was registered after 11,18 , and 7 days of female appearance and nearly continued until female death. While the first case of death was registered for adult females in 72, 91, and 61 days

Table 3 Life table of Cryptolaemus montrouzieri females treated with $\mathrm{LC}_{50}$ concentration of Metarhizium anisopliae

\begin{tabular}{llllllll}
\hline$x$ & $I_{x}$ & $L_{x}$ & $d_{x}$ & $100_{\mathrm{qx}}$ & $s_{x}$ & $T_{x}$ & $e_{x}$ \\
\hline Eggs & 206 & 184.5 & 31 & 15.05 & 84.95 & 724 & 3.51 \\
1st instar & 163 & 139 & 20 & 9.71 & 90.29 & 518 & 3.18 \\
2nd instar & 115 & 100.5 & 17 & 8.25 & 91.75 & 355 & 3.09 \\
3rd instar & 86 & 76 & 6 & 2.91 & 97.09 & 240 & 2.79 \\
4th instar & 66 & 58 & 5 & 2.43 & 97.57 & 154 & 2.33 \\
$\quad$ Pupae & 50 & 44 & 13 & 6.31 & 93.69 & 88 & 1.76 \\
Adults & 38 & 19 & & & & & \\
\hline
\end{tabular}


Table 4 Life table of Cryptolaemus montrouzieri females under control treatment

\begin{tabular}{llllllll}
\hline$x$ & $I_{x}$ & $L_{x}$ & $d_{x}$ & $100_{\mathrm{qx}}$ & $S_{x}$ & $T_{x}$ & $e_{x}$ \\
\hline Eggs & 315 & 300 & 22 & 6.98 & 93.02 & 1598.5 & 5.07 \\
1st instar & 285 & 273 & 20 & 6.35 & 93.65 & 1298.5 & 4.56 \\
2nd instar & 261 & 254.5 & 18 & 5.71 & 94.29 & 1025.5 & 3.91 \\
3rd instar & 248 & 240 & 11 & 3.49 & 96.51 & 771 & 3.11 \\
4th instar & 232 & 225 & 9 & 2.86 & 97.14 & 531 & 2.29 \\
$\quad$ Pupae & 218 & 207.5 & 10 & 3.17 & 96.83 & 306 & 1.4 \\
Adults & 197 & 98.5 & & & & & \\
\hline
\end{tabular}

on emerged females after treatment with $\mathrm{LC}_{50}$ concentration of B. bassiana, M. anisopliae, and distilled water (control), respectively.

The latter female endears on days 77, 94, and 64 . Moreover, results in Table 5 demonstrated that the pre-ovipositional period lasted about 10.13, 17.13, and 6.23 days; ovipositional period lasted about 15.14, 19.21 , and 21.13 days; and post-ovipositional period lasted about 5.14, 2.18, and 3.22 days for female after treatment with $B$. bassiana, $M$. anisopliae, and in the control. The results obtained from Tables 2 to 5 had also supported that the virulence of $M$. anisopliae was higher than $B$. bassiana on fecundity, preovipositional, ovipositional, post-ovipositional periods, and longevity of C. montrouzieri.

Numerous researchers recorded that the fertility, pre-ovipositional, ovipositional, post-ovipositional periods, and life span of $C$. montrouzieri predator were impacted by EPF. Ibrahim et al. (2011) mentioned that M. anisopliae impacted the pre-ovipositional, ovipositional, and post-ovipositional periods of $C$. montrouzieri. Also, Ana et al. (2017) stated that the EPF, B. bassiana, had a great effect on the fecundity of Eriopis connexa (Germar). However, there is a few information about interactions with other natural enemies in coccinellid species in general and C. montrouzieri in particular. Even though, many coccinellid species and EPF may occupy in the same spatial and temporal habitat.

The present study revealed that EPF species greatly affect the biotic processes as growing stages, fertility, and elements of life tables of $C$. montrouzieri. The instinctive ability for the augmentation $(r)$ and the limited average of augmentation $(\lambda)$ of $C$. montrouzieri treated with $\mathrm{LC}_{50}$ concentration of $B$. bassiana, $M$. anisopliae, and the distilled water (control) were significantly different.

The life table elements of the remedied females are visible in Table 6 . The final propagation rates $\left(R_{0}\right)$ in $\mathrm{LC}_{50}$ concentration of $B$. bassiana and $M$. anisopliae were significantly lower than the control $(155.99,115.55$, and 338.82, respectively). Furthermore, the intrinsic rate of increase $\left(r_{m}\right)(0.08,0.06$, and 0.13$)$ and the finite rate of increase $(\lambda)(1.08,1.06$, and 1.14) were less in numerical values than those obtained in the control. Average generation period $(T)$ displayed a clear difference in the $\mathrm{LC}_{50}$ groups of both $B$. bassiana and $M$. anisopliae than the control. The longest average generation period was recorded in $M$. anisopliae and B. bassiana treatments, but the shortest average generation period was registered in the control $(76.78,60.95$, and 43.76). With regard to the productivity of female, it had the highest fertility rate $\left(\Sigma m_{x}\right)(574.9)$ in the control compared to B. bassiana (431.39) and M. anisopliae (360.4).

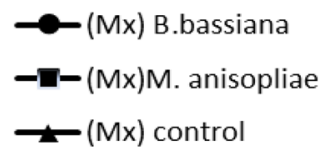

$\longrightarrow$ (Mx) control

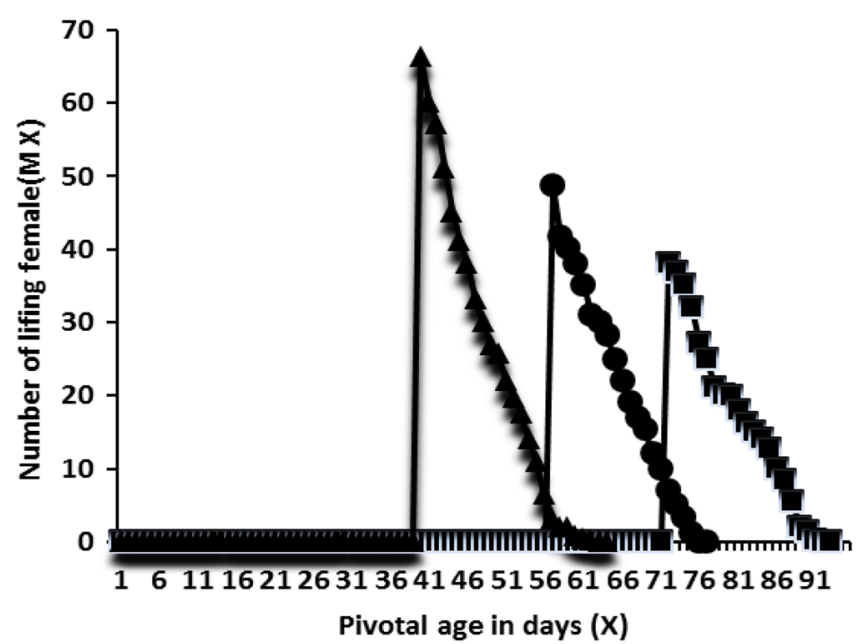

Pivotal age in days $(x)$

Fig. 2 Cryptolaemus montrouzieri female fertility treated with the two tested entomopathogenic fungi (Beauveria bassiana and Metarhizium anisopliae) and the control 
Table $\mathbf{5} L_{50}$ effect of entomopathogenic fungi and control on different life periods of Cryptolaemus montrouzieri

\begin{tabular}{lllll}
\hline Fungi isolates & Duration (day, mean \pm S.E.) & & & \\
\cline { 2 - 4 } & Pre-oviposition period & Oviposition period & Post-oviposition period & $\begin{array}{c}\text { Total life } \\
\text { cycle }\end{array}$ \\
\hline Beauveria bassiana & $10.13 \pm 0.91$ & $15.14 \pm 1.91$ & $5.14 \pm 1.03$ & $77.11 \pm 1.01$ \\
Metarhizium anisopliae & $17.13 \pm 0.92$ & $19.21 \pm 2.51$ & $2.18 \pm 1.16$ & $94.08 \pm 2.15$ \\
Control & $6.23 \pm 1.70$ & $21.13 \pm 1.48$ & $3.22 \pm 1.12$ & $64.11 \pm 3.15$ \\
\hline
\end{tabular}

The outcomes presented in Table 6 displayed that the doubling time $\left(D_{T}\right)$ recorded 8.66, 11.55, and 5.33 in $\mathrm{LC}_{50}$ concentration of $B$. bassiana and $M$. anisopliae treatments and the control, respectively. This is on account of the truth that large numbers of larvae and pupae died before they developed into an adult. This proves that the influence of $M$. anisopliae and B. bassiana was not only active and destructive in a certain treated stadium, but also had an impact on a subsequent stadium furthermore difficulty in molting (Malarvannan et al., 2010). Little researches have been done on the effect of fungus $B$. bassiana on the reproductive factors in ala decline in the fertility of Eriopis connexa predator under laboratory conditions (Ana et al., 2017). The applications of $M$. anisopliae decreased the offspring and affected the duration of survival of Menochilus sexmaculatus adults and prevented the growth of larvae to adult (Trizelia et al., 2017).

Even though the laboratory-reared insects are more oversensitive to pathogens (Hajek and Butler, 2000), the ecological elements and behavioral receptions of the predators should be taken into consideration to clarify the rare rate of EPF infesting coccinellids beneath naturalistic field environment.

\section{Conclusion}

This study demonstrated that a single concentration of the fungi $B$. bassiana and $M$. anisopliae affected the development, fecundity, and life table elements of the predator C. montrouzieri. The concept of the ecological results of utilizing more than one biological control

Table 6 Population and reproductive measurements of Cryptolaemus montrouzieri females

\begin{tabular}{llll}
\hline Parameters & Control & B. bassiana & M. anisopliae \\
\hline$R_{0}$ & 338.82 & 155.99 & 115.55 \\
$T$ & 43.76 & 60.95 & 76.78 \\
$r_{m}$ & 0.13 & 0.08 & 0.06 \\
$\lambda$ & 1.14 & 1.08 & 1.06 \\
$D_{T}$ & 5.33 & 8.66 & 11.55 \\
$\Sigma M_{x}$ & 574.90 & 431.39 & 360.40
\end{tabular}

$R_{o}$ the final propagation rates; $R_{o}=\Sigma l_{x} m_{x} T$ average generation period; $T=\ln$ $R_{o} / r_{m} ; r_{m}$ the instinctive ability for the augmentation, $r=\ln R_{o} / T ; \lambda$ the limited average of augmentation, $\lambda=e^{r} ; D_{T}$ twice the amount time, the number of days required by a population to double, $D_{T}=\ln 2 / r_{m} ; \Sigma M_{x}$ overall reproduction rate agent required exact testing inside intricate ecosystems, which included different species of natural enemies. Such studies are necessary to assist in describing the interactions between entomopathogens and natural enemies to raise and encourage chances in developing biological pest control programs.

\section{Acknowledgements}

The author thanks South Valley University at Qena for the support of this work.

\section{Author's contributions}

I am the only author of this manuscript. So, I am responsible for all the steps. The author read and approved the final manuscript.

\section{Funding}

No funding

Availability of data and materials

The author confirms that all relevant data are included in the article.

Ethics approval and consent to participate

Not applicable.

\section{Consent for publication}

Not applicable.

\section{Competing interests}

The author declares that he has no competing interests.

Received: 3 April 2019 Accepted: 19 June 2019

Published online: 28 June 2019

\section{References}

Ana CS, Sebastian P, Marilina NF, Florencia V, Marcela IS (2017) Interactions between the entomopathogenic fungus Beauveria bassiana and the Neotropical predator Eriopis connexa (Coleoptera: Coccinellidae): implications in biological control of pest. J Plant Protection Res 57(4):389-395

Er MK, Tunaz H, Isikber AA, Satar S, Mart C, Uygun N (2008) Pathogenicity of entomopathogenic fungi to Coccinella septempunctata (Col.: Coccinellidae) and a survey of fungal diseases of Coccinellids. J King Saud Univ Eng Sci 11(1):118-122

Faria MRD, Wraight SP (2007) Mycoinsecticides and mycoacaricides: a comprehensive list with worldwide coverage and international classification of formulation types. Biol Control 43:237-256

Hajek AE, Butler $L$ (2000) Predicting the host range of entomopathogenic fungi. p. 263-273. In: Follett PA, Duan JJ (eds) Nontarget Effects of Biological Control. Kluwer Academic Publisher, Dordrecht, NL

Ibrahim L, Hamieh A, Ghanem H, Ibrahim SK (2011) Pathogenicity of entomopathogenic fungi from Lebanese soils against aphids, whitefly and non-target beneficial insects. Int J Agric Sci 3:156-164

Inglis GD, Goettel MS, Butt TM, Strasser H (2001) Use of hyphomycetous fungi for managing insect pests. In: Butt TM, Jackson C, Magan N (eds) Fungi As Biocontrol Agents: Progress. Problems and Potential. CABI Publising, Bristol, UK, pp 23-70

Jiang RX, Li S, Guo ZP, Pang H (2009) Research status of Cryptolaemus montrouzieri Mulsant and establishing its description criteria. J Environ Entomol 31:238-247 
Kaur H, Virk J (2012) Feeding potential of Cryptolaemus montrouzieri against the mealybug, Phenacoccus solenopsis. Phytoparasitica 40:131-136

Luck RF, Hepard BMS, Enmore PEK (1988) Experimental methods for evaluating arthropod natural enemies. Annu Rev Entomol 33:367-391

Malarvannan S, Murali PD, Shanthakumar SP, Prabavathy VR, Nair S (2010) Laboratory evaluation of the entomopathogenic fungi, Beauveria bassiana against the Tobacco caterpillar, Spodoptera litura Fabricius (Noctuidae: Lepidoptera). J Biopestic 3:126-131

Nalepa CA, Weir A (2007) Infection of Harmonia axyridis (Coleoptera: Coccinellidae) by Hesperomyces virescens (Ascomycetes: Laboulbeniales): role of mating status and aggregation behavior. J Invertebr Pathol 94(3):196-203

Nazir N, Mirza JH, Akhtar N, Bajwa R, Nasim G (2007) Some studies of thermophilic and thermotolerant fungi from Lahore, Pakistan. Mycopath 5(2):95-100

Pang X, Gordon RD (1986) The Scyminini Coleoptera: Coccinellidae of China. Coleopt Bull 40:157-199

Scorsetti AC, Pelizza S, Cabello MN (2012) New records of hypocrealean fungi infecting aphids and whiteflies: pathogenicity against Myzus persicae and interaction with its predator Eriopis connexa. Biocontrol Sci Technol 22(9): 1099-1105

Southwood TRE (1978) Ecological methods with particular reference to the study of insect populations. 2nd ed. Chapman and Hall, London, p 524

Tanada Y, Kaya HK (1993) Insect pathology. Academic Press. Inc., California

Thungrabeab M, Blaeser P, Sengonca C (2006) Effect of temperature and host plant on efficacy of different entomopathogenic fungi from thailand used against Frankliniella occidentalis ( P e r g a n d e ) (Thys., Thripidae) and Thrips tabaci Li n d e ma n (Thys., Thripidae) in the laboratory. J Plant Dis Protect 113(4):181-187

Thungrabeab M, Tongma S (2007) Effect of entomopathogenic fungi, Beauveria bassiana (Balsam) and Metarhizium anisopliae (Metsch)on non-target insects. Kmitl Sci Technol J 7:8-12

Trizelia, Munzir B, Agung P (2017) Pathogenicity of entomopathogenic fungus Metarhizium spp. against predators Menochilus sexmaculatus Fabricius (Coleoptera: Coccinelidae). Asian J Agric 1:1-5

Van Driesche RG, Bellows TS (1996) Biological control. Chapman and Hall, New York, p 539

\section{Publisher's Note}

Springer Nature remains neutral with regard to jurisdictional claims in published maps and institutional affiliations.

\section{Submit your manuscript to a SpringerOpen ${ }^{\circ}$ journal and benefit from:}

- Convenient online submission

- Rigorous peer review

- Open access: articles freely available online

- High visibility within the field

- Retaining the copyright to your article

Submit your next manuscript at $\boldsymbol{\nabla}$ springeropen.com 